Çukurova Üniversitesi Mühendislik Mimarlık Fakültesi Dergisi, 33(3), ss. 31-40, Eylül 2018

Çukurova University Journal of the Faculty of Engineering and Architecture, 33(3), pp. 31-40, September 2018

\title{
Yabancı Algoritmasının Saldırgan Olmayan Seçim Yöntemlerine Uygulanması
}

\author{
Mustafa ORAL ${ }^{*}$, Mashar Cenk GENÇAL ${ }^{1}$ \\ ${ }^{1}$ Çukurova Üniversitesi, Mühendislik Fakültesi, Bilgisayar Mühendisliği Bölümü, Adana
}

$\ddot{O} \mathbf{z}$

Geliş tarihi: $21.06 .2018 \quad$ Kabul tarihi: 15.10 .2018

Optimizasyon problemlerinde sıklıkla kullanılan yöntemlerden biri olan Genetik algoritmalar, rassallıktan yararlanarak, aranan optimum nokta için en uygun bireyleri seçerler. Böylelikle, her bir tekrarlamada en uygun bireyleri seçerek, optimum noktayı bulmayı ya da optimum değere yaklaşmayı amaçlamaktadır. Bundan dolayı, genetik algoritmaların etkili bir biçimde çalışması için iyi bir seçim yöntemine sahip olmak algoritmanın başarımı açısından büyük önem arz etmektedir. Bu çalışmanın amacı, önceden sunmuş olduğumuz Yabancı seçim yönteminin iyileştirilmesidir. Sunulan iyileştirilmiş algoritmanın performansı, önceden sunulmuş olan Saldırgan seçim yöntemleri, Saldırgan olmayan seçim yöntemleri ve Yabancı seçim yöntemi ile yaygın olarak kullanılan seçim yöntemlerinden; rulet tekeri, doğrusal sıralama ve turnuva metotlarının performansları ile karşılaştırılmıştır. Sunulan iyileştirilmiş algoritmanın, kıyaslanan algoritmalar üzerinde bariz üstünlüğü gözlemlenmiştir.

Anahtar Kelimeler: Genetik algoritma, Yabancı algoritması, Saldırgan olmayan seçim yöntemi

\section{Application of Outlander Algortihm on Non-Aggressive Selection Methods}

\begin{abstract}
Genetic Algorithms (GAs), one of the most frequently used methods in optimization problems, stochastically select the appropriate individuals in order to find the optimum point that is searched. By choosing the most appropriate individuals in each iteration, it aims to find the optimum or near optimum point. Hence, it is significantly important to have a decent selection method in order to operate GAs effectively. The goal of this paper is to improve Outlander algorithm which was already proposed. The performance of the improvised Outlander algorithm is compared with previously proposed selection methods; Aggressive, Non-Aggressive selection methods, and the most commonly used standard selection methods; Roulette Wheel, Linear Ranking and Tournament, as well as the Outlander algorithm. It is observed that the improved algorithm has pronounced advantages over the compared algorithms.
\end{abstract}

Keywords: Genetic algorithms Outlander algorithm, Non-aggressive selection method

*Sorumlu yazar (Corresponding author): Mustafa ORAL, moral@cu.edu.tr 


\section{GíRiș}

Genetik algoritmalar, 1975 yilında John Holland tarafından literatüre kazandırılmıştır [1]. Holland, Darwin'in Evrim Teorisinden esinlenmiş ve optimizasyon problemleri için yeni bir model oluşturmuştur. Özellikle arama uzayındaki başarısından dolayı [2], onun bu fikri birçok araştırmacıya ilham kaynağı olmuş ve genetik algoritmalar, optimizasyon problemlerinde sıklıkla kullanılan algoritmalar haline gelmiş̧ir.

Genetik algoritmalar başlangıç bireylerini rastgele tanımlayarak ilk popülasyonu oluştururlar. Optimizasyon probleminde kullanılacak olan uygunluk fonksiyonu yardımıyla, popülasyonda bulunan her bir birey için uygunluk değeri hesaplanır. Bu uygunluk değeri, popülasyondaki bireylerden hangisinin seçileceği hakkında bilgi vereceğinden seçim aşaması için çok önemlidir. Başlangıç popülasyonunun oluşturulmasından sonra sırasıyla üç temel aşama vardır: seçim, çaprazlama ve mutasyon. Çaprazlama ve mutasyon aşamaları, seçim aşamasından daha sonra yapıldı ğı için, seçim yönteminin performansı, diğer aşamaların çalışma performanslarını etkileyecektir. Bundan dolayı, iyi bir seçim yöntemine sahip olmak, genetik algoritmasının etkili bir şekilde çalışmasını sağlayacaktır. Seçim aşamasının görevi, verilen optimizasyon problemi için en uygun bireyleri seçmek ve çaprazlama aşamasına seçilen bu bireyleri göndermektir. Genellikle, seçim yöntemleri popülasyon içindeki en iyi bireyleri, en yüksek uygunluk değerine sahip bireyleri, seçme eğilimindedirler. Çaprazlama aşamasında ise, seçilen iyi bireylerden yeni birey ya da bireyler elde edilir [3]. Genetik algoritmaların en son aşaması olan mutasyon aşamasında ise bireylerin genetik yapıları değiştirilerek yeni bireyler elde edilir. Mutasyon işleminin temel amacı, genetik çeşitliliği korumak ve lokal minimum değerine erken yakınsamayı önlemektir [3]. Son olarak, elde edilen bireyler ile mevcut popülasyondaki en iyi bireyler belirli oranda karıştırılarak yeni bir popülasyon oluşturulur. Bu süreç, istenilen kritere ulaşana kadar ya da elde edilmek istenen sonuç bulunana kadar devam ettirilir.
Yukarıda bahsedilen genetik algoritmanın aşamaları göz önüne alındığında, iyi bir seçim yöntemine sahip olmanın ne kadar önemli olduğu açıktır. Bundan dolayı, yaptığımız çalışmada, önceden sunmuş olduğumuz Yabancı (Outlander) seçim yöntemini [4] iyileştirerek daha etkili bir seçim yöntemi elde etmek amaçlanmaktadır. Önerilen iyileştirmenin performansa katkısını belirlemek için, daha önceden önerdiğimiz; Saldırgan ve Saldırgan olmayan seçim yöntemleri ile yaygın olarak kullanılan; rulet tekeri, doğrusal sıralama ve turnuva seçim yöntemlerinin başarım performansları test fonksiyonları üzerinde ölçülmüş ve karşılaştırmalı olarak sunulmuştur.

$\mathrm{Bu}$ makalenin organizasyonu şu şekildedir: İkinci bölümde, literatürde yaygın olarak kullanılan seçim yöntemleriyle ilgili bilgiler sunulmuş ve üçüncü bölümde araştırmamıza esin kaynağı olan önceki çalışmalarımız tanıtılmıştır. Dördüncü bölümde Yabancı algoritması üzerine yaptığımız iyileştirmeler arz edilirken, beşinci bölümde kullanılan test fonksiyonları, yapılan testler ve sonuçları gösterilmiştir.

\section{2. ÖNCEKİ ÇALIŞMALAR}

Rulet Tekeri (Roulette Wheel), Genetik algoritmalar için önerilen ilk seçim yöntemlerinden biridir [1]. Kullanımı kolay olan bir yöntem olmasına rağmen, algoritmanın erken yakınsamasına neden olabilmektedir.

Doğrusal Sıralama yöntemi (Linear Ranking), Rulet tekerinin olumsuz yönlerine çözüm bulmak için sunulan bir yöntemdir [5]. Ancak, bu yöntem beraberinde farklı problemlere; popülasyonun daha yavaş yakınsamasına ve popülasyonunun her bir tekrarlamada sıralanmasını gerektirdiği için zaman kaybına neden olmuştur.

Turnuva yöntemi, Genetik algoritmalarda sıklıkla kullanılan yöntemlerden biridir. Bunun nedeni, turnuva yönteminin zaman karmaşıklığının düşük olması, paralel programlama için uygun olması ve seçim baskısını ayarlayabilmesidir. Fakat yöntemin, uygunluk fonksiyonunun birden fazla 
lokal minimum değerine sahip olduğu durumlarda, lokal minimum değere sıkışması kuvvetli ihtimaldir [6].

Goldberg, Benzetilmiş Tavlamanın (Simulated Annealing) kullandığı Boltzmann dağılımından ve sıcaklık değerinden esinlenerek Boltzmann Turnuva Seçim yöntemini sunmuştur [7]. Goldberg, Boltzmann dağılımını kullanarak, en iyi sonuca adım adım ulaşmayı arzulamıştır.

Harik, Genetik algoritmalardaki çok modlu optimizasyon problemleri için Sinırlı Turnuva yöntemini (Restricted Tournament Selection) geliştirmiştir [8]. Bu yöntemde, önceden belirlenmiş bir komşuluk alanı boyunca turnuva ile seçilen bireylerin çevreleri incelenmiş, bu inceleme sonucunda turnuva ile seçilen bireyin çevresinde daha iyi bir komşusu varsa, seçilen birey komşusuyla değiştirilmiştir.

Matsui, Bağlantılı Turnuva Seçim yöntemini (Correlative Tournament Selection) tanitarak popülasyondaki çeşitliliği korumayı amaçlamıştır [9]. İlk birey standart turnuva yöntemiyle seçilirken, ikinci birey bu yöntemle seçilmektedir: Popülasyon içinden rastgele seçilen belli sayıdaki bireylerin bağıntı fonksiyonu yardımıyla değerleri hesaplanmakta ve bu değerlere göre en uygun olan birey, ikinci birey olarak seçilmektedir.

De La Maza ve Tidor, temeli uygun sicaklık değerinin seçilmesine dayanan Boltzmann seçim yöntemini (Boltzmann Selection) sunmuşlardır [10]. Seçilen yüksek sicaklık değeri sayesinde seçim baskısı düşük tutulur ve böylece sadece en iyi birey değil, tüm bireyler de seçilme şansına sahip olurlar. Daha sonra, bu değer kademe kademe azaltılarak, seçim baskısı artırılır ve böylelikle bulunan iyi değerlere odaklanma sağlanır.

1995 yılında Pohlheim tarafından ortaya atılan Bölgesel seçim yöntemi, bölgesel komşuluk ilkesine dayanır [11]. Her bir birey, sadece kendi komşuluğunda yer alan bireyler ile eşleşebilmektedir. Yapılan testlerin sonucunda, bu yöntemin az nüfusa sahip popülasyonlarda etkili olmadığı görülmüştür

\section{ESIN KAYNAĞI OLAN ÇALIŞMALAR}

\subsection{Saldırgan Seçim Yöntemi}

Genetik algoritmanın optimizasyon performans1 üzerinde büyük etkisi olan seçim yöntemi üzerinde yapılan önemli çalışmalara "Önceki Çalışmalar" kısmında bahsetmiştik. Yakın zamanda önerdiğimiz [6] ve konuya katkı sağlayan Saldırgan Seçim yöntemi, uygulamadaki kolaylığı ve eş seçiminde bireylerin birbirlerini reddedebilme yetenekleriyle, doğadan gözlemlediğimiz eş seçimi davranışına daha yakındır.

Saldırgan seçim yönteminin (Agressive Selection Method, ASM) prensibine göre, bir birey yalnızca kendisinden daha iyi ya da kendisine eşit uygunluk değerine sahip bir bireyle eşleşebilmektedir [6]. Örneğin bir minimizasyon probleminde, uygunluk değeri 5 olan bir bireyin rasgele seçildiğini varsayalım. Seçilen bu ilk bireye eş olmaya aday ikinci birey rasgele seçilecek ve uygunluk değeri kontrol edilecektir. Eğer uygunluk değeri birinci eşin uygunluğuna eşit ya da daha küçük ise (minimizasyon problemi için) bu iki birey arasında eşleşme gerçekleştirilecektir diğer durumda bireyler birbirlerini reddedecek ve işleme yeni iki birey seçilerek devam edilecektir. Eşleştirmeler sonucunda yeni bir popülasyon oluşturuluncaya kadar bu işlem devam edecektir. Algoritmanın sözde kodu aşağıda verilmiştir. Eşleşme işlemi seçim yönteminden bağımsız olduğu için, arzu edilen herhangi bir eşleşme yöntemi seçilebilir.

count $=1$

while count $<=$ population size

Randomly choose first and second mate Determine costs of first and second mate If cost (second mate) $<=$ cost (first mate) Allow mating count $=$ count +1 ;

Else

end

end 


\subsection{Saldırgan Olmayan Seçim Yöntemi}

ASM yönteminin en büyük dezavantajı, ilk birey iyi bir uygunluk değerine sahip birey olarak seçildiğinde, seçilen bu ilk bireye uygun bir birey bulunana kadar, işlemin tekrar tekrar yapılmasına neden olmakta ve bu da zaman kaybına yol açmaktadır. Bundan dolayı, Saldırgan olmayan seçim yöntemi (Non-Agressive Selection Method, NASM) geliştirilmiştir [6]. Yöntem, ikinci birey birinci bireyden daha iyi uygunluk değerine sahip olmasa dahi ikinci bireye eşleşmeye katılma şansı tanıyarak tekrar sayısını azaltmakla birlikte, farklı bireylere de daha fazla çiftleşme şansı tanıdığından çeşitliliği artırmaktadır. Çiftleşme olasılığı, De la Maza ve Tidor'un çalışmasında olduğu gibi [10], bir sıcaklık rejimine bağlıdır. Isının yüksek olduğu zamanlarda seçim baskısı düşük ve zaman içerisinde yükselmektedir. Algoritmanın sözde kodu incelendiğinde, ASM den farklı olarak bir olasılık değeri, "the probability", eklendiği görülmektedir. Bu değer sayesinde, birinci birey ikinci bireyden daha düşük bir uygunluk değerine sahip olsa bile, rasgele atılan bir sayının, olasılık değerinden daha düşük olduğu durumlarda, birinci bireyin ikinci bireyle eşleşmesi yapılabilmektedir.

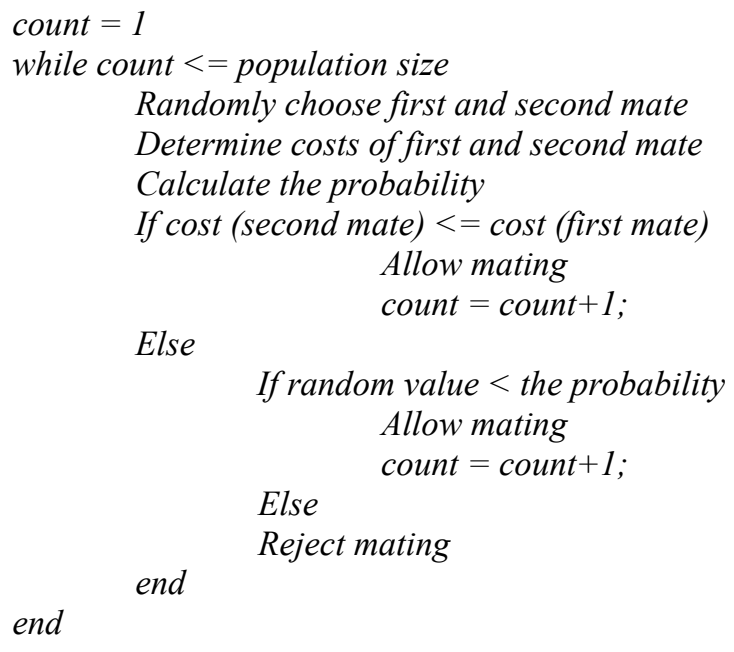

\subsection{Bütünleşik Saldırgan Seçim Yöntemi}

Saldırgan olmayan seçim yöntemindeki iyileştirmeden farklı olarak, Bütünleşik Saldırgan seçim yönteminde (Integrated Agressive Selection
Method, IASM), turnuva yöntemi ile ASM yöntemi karıştırılarak, ASM den daha başarılı bir seçim yöntemi elde etme amaçlanmıştır [6]. Önerilen yöntemde Matsui nin sunmuş olduğu Bağlantılı Turnuva Seçim Yönteminde olduğu gibi [9], ilk birey turnuva yöntemiyle seçilirken, ikinci bireyin seçimi için ASM yönteminin kullanılması tercih edilmiştir. Birinci bireyin seçiminde, Turnuva yönteminin kullanılmasının nedeni, zaman karmaşıklığının düşüklüğü $(O(n))$ ve genetik algoritmalar üzerindeki başarılı sonuçlarıdır. Algoritma aşağıda verilen sözde koduna bakıldığında, ASM yönteminde bulunan, ilk bireyin rasgele seçim kısmının kaldırılarak, yerine turnuva yöntemi eklendiği görülebilmektedir:

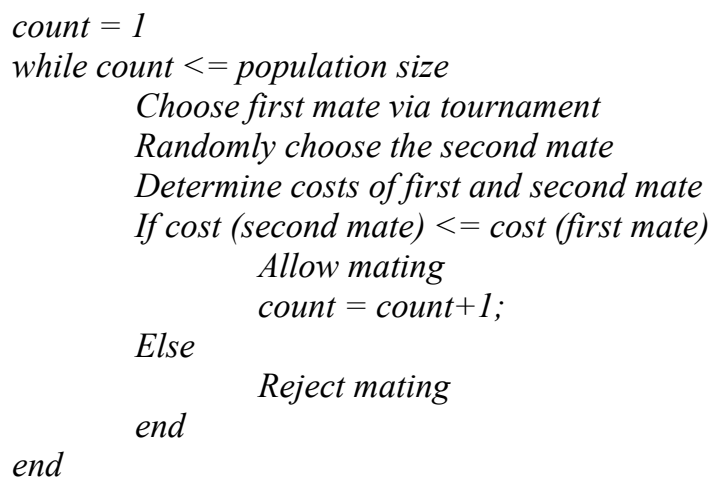

\subsection{Saldırgan Olmayan Bütünleşik Seçim Yöntemi}

Saldırgan olmayan bütünleşik seçim yöntemi (Integrated Non-Agressive Selection Method, INASM) ise IASM yönteminin geliştirilmiş halidir [6]. NASM de kullanılan sıcaklık rejiminin seçim baskısı üzerine etkileri burada da uygulanmış ve başarılı sonuçlar elde edilmiştir. INASM algoritmasının aşağıda verilen çalışma prensibi dikkate alındığında, IASM den farkının, NASM de kullanılan olasılık değeriyle ilgili bölümün, INASM de de kullanılması olduğu açık bir şekilde görülmektedir:

count $=1$

while count $<=$ population size

Choose first mate via tournament

Randomly choose second mate 
Determine costs of first and second mate

Calculate the probability

If cost (second mate) $<=$ cost (first mate)

$$
\begin{aligned}
& \text { Allow mating } \\
& \text { count }=\text { count }+1 \text {; }
\end{aligned}
$$

Else

If random value $<$ the probability

Allow mating

count $=$ count +1

Else

end

\section{Reject mating}

end

\subsection{Yabancı Seçim Yöntemi}

IASM yöntemini geliştirmek için sunulan INASM yöntemi ile her ne kadar başarılı sonuçlar alınmış olsa da zaman kaybina neden olan etmenler tamamıyla ortadan kaldırılamamıştır. Bu nedenle, IASM yönteminde mevcut olan eş reddetme prosedürünü ortadan kaldırmak ve yöntemin daha etkin bir şekilde çalışmasını sağlamak amacıyla Yabancı seçim yöntemi sunulmuştur [4]. Yabancı seçim yöntemi ile IASM yöntemleri arasındaki önemli fark, Yabancı seçim yönteminin algoritmaya eş reddetme şansı tanımamasıdır. $\mathrm{Bu}$ yöntemde, birinci birey ikinci seçilen bireyi reddetmek istediğinde, popülasyondan bağımsız olan "yabancı" bir birey yaratılır ve birinci bireyin bu bireyle çaprazlanması zorunlu tutulur. Algoritmanın işleyişi incelendiğinde, birinci bireyin ikinci bireyi kabul etmediği durumlarda, popülasyondan bağımsız yeni bir bireyin rasgele oluşturularak, birinci bireyle oluşan bu yeni bireyin eşleşmeye zorlandığ görülebilmektedir:

count $=1$

while count $<=$ population size

Choose first mate via tournament

Randomly choose second mate

Determine costs of first and second mate

If cost (second mate) $<=$ cost (first mate)

Second mate is chosen

Else

Create a new individual as the second mate

End end $\quad$ count $=$ count +1 ;

\section{4. ÖNERİLEN YÖNTEM}

Yabancı Seçim Yöntemi sayesinde popülasyondaki çeşitlilik artmış ve önceden sunmuş olduğumuz çalışmalardan [6] daha iyi sonuçlar elde edilmiştir. Ancak, daha da iyi bir seçim yöntemine ulaşmak amacıyla, Yabancı seçim yönteminde var olan ikinci birey seçimi, INASM'den esinlenerek değiştirilmiş ve ortaya yeni bir yöntem olan Agresif Olmayan Yabancı Seçim Yöntemi (N-OA) çıkarılmıştır. Yabancı algoritmasının doğası gereği, eș reddetme işleminin ortadan kalkması, bir sonraki popülasyonun elde edilmesinde ASM, NASM, IASM ve INASM algoritmalarının yaşadığı gecikmeyi ortadan kaldırmaktadır. Yabancı IASM tabanlı bir algoritma iken N-OA algoritması INASM tabanlıdır. Isı rejiminin Yabanc1 algoritmasına entegre edilmesiyle, uygun olmayan eşlerin de gen aktarımına katkısı sağlanmış ve genetik çeşitlilik popülasyon içi ve dışı eşlerin eklenmesiyle zenginleştirilmiştir. Aşağıda verilen Agresif olmayan Yabancı algoritmasının çalışma prensibine bakıldığında, yabancı algoritmasından tek farkının NASM de de kullanılan olasılık değeri ile ilgili bölüm olduğu aşikardır:

count $=1$

while count $<=$ population size

Choose first mate via tournament

Randomly choose second mate

Determine costs of first and second mate

Calculate the probability

If cost (second mate) $<=$ cost (first mate)

Individuals mate

Else

If random value $<$ the probability Individuals mate

Else

Create a new individual as the second mate

End

count $=$ count +1 ;

end 
Çizelge 1. Test fonksiyonları ve türleri

\begin{tabular}{|c|l|c|}
\hline \multirow{2}{*}{$\begin{array}{c}\text { Fonksiyon } \\
\text { No }\end{array}$} & \multicolumn{2}{|c|}{ Test Fonksiyonları ve Türleri } \\
\cline { 2 - 3 } & Fonksiyonun Adı & \multicolumn{1}{c|}{ Türü } \\
\hline$f_{1}$ & Ackley & Çok Modlu \\
\hline$f_{2}$ & $\begin{array}{l}\text { Axis Parallel Hyper } \\
\text { Ellipsoid }\end{array}$ & Tek Modlu \\
\hline$f_{3}$ & Branins & Çok Modlu \\
\hline$f_{4}$ & De Jong & Tek Modlu \\
\hline$f_{5}$ & Goldstein-Price & Tek Modlu \\
\hline$f_{6}$ & Langermann & Çok Modlu \\
\hline$f_{7}$ & Rastrigin & Çok Modlu \\
\hline$f_{8}$ & Rosenbrock's Valley & Tek Modlu \\
\hline$f_{9}$ & Schwefel & Çok Modlu \\
\hline$f_{10}$ & $\begin{array}{l}\text { Sum of Different } \\
\text { Powers }\end{array}$ & Tek Modlu \\
\hline & & \\
\hline
\end{tabular}

\section{TESTLER}

\subsection{Test Fonksiyonları}

Önerilen seçim yönteminin performansını test etmek için, evrimsel algoritmalar alanında çalışan araştırmacılar tarafından yaygın kabul görmüş optimizasyon test fonksiyonlarından [12] Çizelge 1'de belirtilen on fonksiyon kullanılmıştır. $\mathrm{Bu}$ fonksiyonlar tek modlu ve çok modlu olmak üzere iki çeşittir. Tek modlu fonksiyonlar, çok modlu fonksiyonlara göre daha duyarlıdır [12]. Bundan dolayı, adım adım ilerleyerek global değere ulaşmak mümkündür. Çok modlu fonksiyonlar ise birden fazla yerel ekstremum değerinin olduğu fonksiyonlardır. Bu yerel ekstremumlar dışında tek ya da daha fazla sayıda global ekstremumlara da sahiptirler. Bu yerel extremumlardan birisine erken yakınsanması problemi optimizasyon algoritmalarının ciddi sorunudur [4].

Ackley fonksiyonunun test alanı genellikle $-32,768 \leq \mathrm{x}_{\mathrm{i}} \leq 32,768, \quad \mathrm{i}=1, \ldots, \mathrm{n} \quad$ bölgesinde sınırlandırılmıştır. Global minimum değer olan $\mathrm{f}_{1}=0$ değerine, $x_{i}=0, i=1, \ldots, n$ için ulaşılabilir.
Axis Parallel Hyper Ellipsoid fonsiyonunda test alanı genellikle $-5,12 \leq \mathrm{x}_{\mathrm{i}} \leq 5,12, \mathrm{i}=1, \ldots, \mathrm{n}$ bölgesinde sınırlandırılmıştır. Global minimum değer olan $\mathrm{f}_{2}=0$ değerine, $\mathrm{x}_{\mathrm{i}}=0, \mathrm{i}=1, \ldots, \mathrm{n}$ için ulaşılabilir.

Branins fonksiyonunda ise global minimum değer olan $\mathrm{f}_{3}=0,397887$ değerine $(-\pi, 12,275),(\pi, 2,275)$ ve $(9,42478,2,475)$ noktalarında ulaşılabilir.

De Jong fonksiyonunda test alanı genellikle $-5,12 \leq \mathrm{x}_{\mathrm{i}} \leq 5,12, \quad \mathrm{i}=1, \ldots, \mathrm{n} \quad$ bölgesinde sinırlandırılmıştır. Global minimum değer olan $\mathrm{f}_{4}=0$ değerine, $x_{i}=0, i=1, \ldots, n$ için ulaşılabilir.

Goldstein-Price fonksiyonunda test alanı genellikle $-2 \leq x_{\mathrm{i}} \leq 2, \mathrm{i}=1,2$ bölgesinde sinırlandırılmıştır. Global minimum olan $\mathrm{f}_{5}=0$ değerine, $(0,-1)$ noktasında ulaşılabilir.

Langermann fonksiyonunun lokal minimum değerleri düzensiz bir şekilde dağılmıştır.

Rastrigin fonksiyonunda test alanı genellikle $-5,12 \leq \mathrm{x}_{\mathrm{i}} \leq 5,12 \quad \mathrm{i}=1, \ldots, \mathrm{n} \quad$ bölgesinde sınırlandırılmıştır. Global minimum değer olan $\mathrm{f}_{7}=0$ değerine, $\mathrm{x}_{\mathrm{i}}=0, \mathrm{i}=1, \ldots, \mathrm{n}$ için ulaşılabilir.

Rosenbrock's Valley fonksiyonunda test alan genellikle $-2,048 \leq x_{i} \leq 2,048, i=1, \ldots, n$ bölgesinde sınırlandırılmıştır. Global minimum değer olan $\mathrm{f}_{8}=0$ değerine, $\mathrm{x}_{\mathrm{i}}=0, \mathrm{i}=1, \ldots, \mathrm{n}$ için ulaşılabilir.

Schwefel fonksiyonunda test alanı genellikle $-500 \leq x_{i} \leq 500, \quad i=1, \ldots, n \quad$ bölgesinde sınırlandırılmıştır. Global minimum değer olan $\mathrm{f}_{9}=-418,9829 * \mathrm{n}$ değerine, $\mathrm{x}_{\mathrm{i}}=420,9687, \mathrm{i}=1, \ldots, \mathrm{n}$ için ulaşılabilir.

Sum of Different Powers fonksiyonunda test alanı genellikle $-1 \leq \mathrm{x}_{\mathrm{i}} \leq 1, \quad \mathrm{i}=1, \ldots, \mathrm{n}$ bölgesinde sınırlandırılmış̧ır. Global minimum değer olan $\mathrm{f}_{10}=0$ değerine, $\mathrm{x}_{\mathrm{i}}=0, \mathrm{i}=1, \ldots, \mathrm{n}$ için ulaşıllabilir.

\subsection{Test Sonuçları}

Testler yapılırken, tüm seçim yöntemlerine eşit koşul sunmak için, literatürde yaygın olarak 
kullanılan "standart parametre değerleri" [13] kullanılmıştır: çaprazlama olasılığ 0,7 , mutasyon olasılığ1 0,05 , popülasyon büyüklüğü 50 ve 100 . Yapılan testlerin doğruluğunu ve güvenirliliğini sağlamak için her bir seçim yöntemi 25 defa ve her seferinde farklı rastgele değerlerle çalıştırılmıştır. Çizelgelerde sunulan sonuçlar bu 25 çalıştırmanın medyan ve çeyrekler açıklığı değerleridir. Test sonuçlarını incelerken hangi yöntemin daha başarılı olduğuna karar vermek için medyan değeri kullanılmıştır. Sonuçları yorumlamada ortalama değerin kullanılmamasının nedeni, tekrarların birinde yüksek bir değer gelmesi halinde ortalama yükselecek ve diğer 24 tekrarda düşük sonuçlar bile almış olsak, bu durum diğer iyi sonuçları yorumlamamıza olanak vermeyecek olmasıdır [5].
Aşağıda verilen çizelgelerde (Çizelge 2-5) yapılan testlerin sonuçları görülmektedir. Tek modlu fonksiyonlarda popülasyon büyüklüğü 50 seçildiğinde N-OA'nın en iyi sonuçları verdiği gözlemlenmiştir. Popülasyon büyüklüğü 100 olduğunda Axis Parallel Hyper Ellipsoid ve De Jong fonksiyonları hariç yine en iyi sonuçlara ulaşılmıştır. Çok modlu fonksiyonlarda popülasyon büyüklüğü 50 olduğunda önerilen N-OA algoritması tüm algoritmalar içerisinde en iyi sonuçları üretmiştir. Popülasyon büyüklüğü 100 olduğunda ise, Ackley fonksiyonu hariç N-OA en iyi sonuçları yine bulmuştur. Ackley fonksiyonunda ise N-OA'nın sonucu kötü olmamakla birlikte en iyi ikinci sonuç olmuştur. Çizelge 4 ve 5 'de görüldüğü üzere N-OA'nın çok modlu fonksiyonlarda diğer algoritmalara karşı bariz üstünlüğü vardır.

Çizelge 2. Popülasyon büyüklüğü 50 için tek-modlu fonksiyonların sonuçları

\begin{tabular}{|c|c|c|c|c|c|c|c|c|c|c|}
\hline \multirow[b]{2}{*}{ METOT } & \multicolumn{2}{|c|}{$\begin{array}{c}\text { Axis Parallel } \\
\text { Hyper Ellipsoid }\end{array}$} & \multicolumn{2}{|c|}{ De Jong } & \multicolumn{2}{|c|}{ Goldstein-Price } & \multicolumn{2}{|c|}{ Rosenbrock's Valley } & \multicolumn{2}{|c|}{$\begin{array}{c}\text { Sum of Different } \\
\text { Powers }\end{array}$} \\
\hline & Medyan & $\begin{array}{c}\text { Çeyreklikler } \\
\text { Açıklığı }\end{array}$ & Medyan & $\begin{array}{c}\text { Çeyreklikler } \\
\text { Açıklığı }\end{array}$ & Medyan & $\begin{array}{c}\text { Çeyreklikler } \\
\text { Açıklığı }\end{array}$ & Medyan & $\begin{array}{c}\text { Çeyreklikler } \\
\text { Açıklığı }\end{array}$ & Medyan & $\begin{array}{c}\text { Çeyreklikler } \\
\text { Açıklığı }\end{array}$ \\
\hline ASM & $2,84 \mathrm{E}-02$ & $1,89 \mathrm{E}-01$ & $1,39 \mathrm{E}-02$ & $2,63 \mathrm{E}-02$ & $3,49 \mathrm{E}+00$ & $1,48 \mathrm{E}+00$ & $3,25 \mathrm{E}-02$ & $8,32 \mathrm{E}-02$ & $3,34 \mathrm{E}-06$ & $8,02 \mathrm{E}-06$ \\
\hline NASM & 4,64E-03 & $1,80 \mathrm{E}-02$ & $2,59 \mathrm{E}-04$ & $3,24 \mathrm{E}-03$ & $3,11 \mathrm{E}+00$ & $7,08 \mathrm{E}-01$ & $1,31 \mathrm{E}-02$ & 4,39E-02 & $7,36 \mathrm{E}-08$ & 7,07E-07 \\
\hline IASM & $6,02 \mathrm{E}-03$ & $5,84 \mathrm{E}-02$ & 4,91E-04 & $3,39 \mathrm{E}-03$ & $3,11 \mathrm{E}+00$ & $5,88 \mathrm{E}-01$ & $1,21 \mathrm{E}-02$ & 7,54E-02 & $1,08 \mathrm{E}-07$ & $5,72 \mathrm{E}-06$ \\
\hline INASM & $1,46 \mathrm{E}-03$ & $8,78 \mathrm{E}-03$ & $1,06 \mathrm{E}-04$ & $1,14 \mathrm{E}-03$ & $3,01 \mathrm{E}+00$ & $4,61 \mathrm{E}-02$ & $4,06 \mathrm{E}-02$ & $1,56 \mathrm{E}-01$ & $1,04 \mathrm{E}-07$ & $4,52 \mathrm{E}-07$ \\
\hline RW & $2,24 \mathrm{E}-02$ & $5,08 \mathrm{E}-02$ & $1,22 \mathrm{E}-03$ & $3,87 \mathrm{E}-03$ & $3,03 \mathrm{E}+00$ & $3,16 \mathrm{E}-01$ & $6,00 \mathrm{E}-02$ & $1,36 \mathrm{E}-01$ & $5,42 \mathrm{E}-07$ & 2,41E-06 \\
\hline LR & $2,82 \mathrm{E}-03$ & $1,35 \mathrm{E}-02$ & $8,05 \mathrm{E}-05$ & 7,83E-04 & $3,04 \mathrm{E}+00$ & 1,99E-01 & $4,21 \mathrm{E}-02$ & $1,33 \mathrm{E}-01$ & $2,47 \mathrm{E}-08$ & $1,38 \mathrm{E}-06$ \\
\hline Tour. & $1,29 \mathrm{E}-02$ & $7,69 \mathrm{E}-02$ & $1,26 \mathrm{E}-03$ & $2,75 \mathrm{E}-03$ & $3,19 \mathrm{E}+00$ & $4,32 \mathrm{E}-01$ & $5,02 \mathrm{E}-02$ & $1,60 \mathrm{E}-01$ & $2,15 \mathrm{E}-06$ & $1,05 \mathrm{E}-05$ \\
\hline OA & $1,26 \mathrm{E}-03$ & $5,41 \mathrm{E}-03$ & $1,72 \mathrm{E}-04$ & 4,07E-04 & $3,00 \mathrm{E}+00$ & 2,88E-03 & $1,73 \mathrm{E}-03$ & $6,04 \mathrm{E}-03$ & $3,67 \mathrm{E}-08$ & 1,39E-06 \\
\hline N-OA & $6,45 \mathrm{E}-05$ & 9,59E-04 & 7,79E-06 & 5,39E-05 & $3,00 \mathrm{E}+00$ & 7,44E-04 & 9,04E-04 & 1,07E-02 & 1,21E-09 & 5,91E-09 \\
\hline
\end{tabular}

Çizelge 3. Popülasyon büyüklüğü 100 için tek-modlu fonksiyonların sonuçları

\begin{tabular}{|c|c|c|c|c|c|c|c|c|c|c|}
\hline \multirow[b]{2}{*}{ METOT } & \multicolumn{2}{|c|}{$\begin{array}{c}\text { Axis Parallel Hyper } \\
\text { Ellipsoid }\end{array}$} & \multicolumn{2}{|c|}{ De Jong } & \multicolumn{2}{|c|}{ Goldstein-Price } & \multicolumn{2}{|c|}{ Rosenbrock's Valley } & \multicolumn{2}{|c|}{$\begin{array}{c}\text { Sum of Different } \\
\text { Powers }\end{array}$} \\
\hline & Medyan & $\begin{array}{c}\text { Çeyreklikler } \\
\text { Açıklığı }\end{array}$ & Medyan & $\begin{array}{c}\text { Çeyreklikler } \\
\text { Açıklığı }\end{array}$ & Medyan & $\begin{array}{c}\text { Çeyreklikler } \\
\text { Açıklığı }\end{array}$ & Medyan & $\begin{array}{c}\text { Çeyreklikler } \\
\text { Açıklığı }\end{array}$ & Medyan & $\begin{array}{c}\text { Çeyreklikler } \\
\text { Açıklı̆̆ }\end{array}$ \\
\hline ASM & $1,17 \mathrm{E}-02$ & 4,37E-02 & $9,06 \mathrm{E}-04$ & 7,94E-03 & $3,04 \mathrm{E}+00$ & $1,02 \mathrm{E}-01$ & 7,07E-03 & 2,74E-02 & $8,39 \mathrm{E}-07$ & $2,02 \mathrm{E}-06$ \\
\hline NASM & 1,92E-03 & $1,33 \mathrm{E}-02$ & $1,51 \mathrm{E}-05$ & $8,07 \mathrm{E}-05$ & $3,00 E+00$ & 2,57E-02 & $7,49 \mathrm{E}-03$ & $3,13 \mathrm{E}-02$ & $7,15 \mathrm{E}-09$ & $1,48 \mathrm{E}-07$ \\
\hline IASM & 2,68E-08 & 3,30E-04 & $1,62 \mathrm{E}-08$ & $4,19 \mathrm{E}-05$ & $3,00 E+00$ & $8,23 E-03$ & $3,26 \mathrm{E}-04$ & $1,23 \mathrm{E}-02$ & $1,86 \mathrm{E}-09$ & $6,31 \mathrm{E}-08$ \\
\hline INASM & 1,92E-06 & $9,47 \mathrm{E}-05$ & $7,75 \mathrm{E}-11$ & $3,47 E-06$ & $3,00 E+00$ & $1,95 \mathrm{E}-03$ & $1,39 \mathrm{E}-02$ & $7,83 \mathrm{E}-02$ & $5,65 \mathrm{E}-12$ & $2,73 \mathrm{E}-10$ \\
\hline RW & $1,21 \mathrm{E}-03$ & $1,24 \mathrm{E}-02$ & $6,93 \mathrm{E}-05$ & $1,02 \mathrm{E}-03$ & $3,00 E+00$ & $1,05 \mathrm{E}-02$ & $1,79 \mathrm{E}-02$ & $7,51 \mathrm{E}-02$ & $1,85 \mathrm{E}-07$ & $1,23 \mathrm{E}-06$ \\
\hline LR & $3,43 \mathrm{E}-04$ & $2,71 \mathrm{E}-03$ & $3,94 \mathrm{E}-06$ & $2,52 \mathrm{E}-04$ & $3,01 \mathrm{E}+00$ & 4,94E-02 & $1,44 \mathrm{E}-02$ & $6,27 \mathrm{E}-02$ & $4,66 \mathrm{E}-10$ & $3,29 \mathrm{E}-08$ \\
\hline Tour. & 5,91E-05 & $2,10 \mathrm{E}-03$ & $5,40 \mathrm{E}-06$ & $2,05 \mathrm{E}-04$ & $3,01 \mathrm{E}+00$ & $1,76 \mathrm{E}-02$ & $6,96 \mathrm{E}-03$ & $3,85 \mathrm{E}-02$ & $9,91 \mathrm{E}-10$ & $3,48 \mathrm{E}-08$ \\
\hline OA & $6,67 \mathrm{E}-05$ & $6,25 \mathrm{E}-04$ & $2,61 \mathrm{E}-05$ & $1,16 \mathrm{E}-04$ & $3,00 \mathrm{E}+00$ & $1,07 E-03$ & $6,91 \mathrm{E}-05$ & $5,48 \mathrm{E}-04$ & $2,54 \mathrm{E}-09$ & $3,33 \mathrm{E}-08$ \\
\hline N-OA & $3,48 \mathrm{E}-06$ & $1,40 \mathrm{E}-05$ & $2,86 \mathrm{E}-08$ & $2,72 \mathrm{E}-07$ & $3,00 E+00$ & $6,24 \mathrm{E}-06$ & 1,58E-05 & $1,64 \mathrm{E}-04$ & $5,07 \mathrm{E}-12$ & $1,24 \mathrm{E}-10$ \\
\hline
\end{tabular}


Çizelge 4. Popülasyon büyüklüğü 50 için çok-modlu fonksiyonların sonuçları

\begin{tabular}{|c|c|c|c|c|c|c|c|c|c|c|}
\hline & \multicolumn{2}{|c}{ Ackley } & \multicolumn{2}{c|}{ Langermann } & \multicolumn{2}{c|}{ Rastrigin } & \multicolumn{2}{c|}{ Schwefel } & \multicolumn{2}{c|}{ Branins } \\
\hline METOT & Medyan & $\begin{array}{c}\text { Çeyreklikler } \\
\text { Açıklı̆ı }\end{array}$ & Medyan & $\begin{array}{c}\text { Çeyreklikler } \\
\text { Açıklğı }\end{array}$ & Medyan & $\begin{array}{c}\text { Çeyreklikler } \\
\text { Açıklı̆ı }\end{array}$ & Medyan & $\begin{array}{c}\text { Çeyreklikler } \\
\text { Açılı̆ı̆ı }\end{array}$ & Medyan & $\begin{array}{c}\text { Çeyreklikler } \\
\text { Açıklı̆ı }\end{array}$ \\
\hline ASM & $1,03 \mathrm{E}+00$ & $2,05 \mathrm{E}+00$ & $-4,04 \mathrm{E}+00$ & $3,48 \mathrm{E}-01$ & $1,47 \mathrm{E}+00$ & $1,03 \mathrm{E}+00$ & $2,05 \mathrm{E}+00$ & $-4,04 \mathrm{E}+00$ & $3,48 \mathrm{E}-01$ & $1,47 \mathrm{E}+00$ \\
\hline NASM & $3,14 \mathrm{E}-01$ & $1,01 \mathrm{E}+00$ & $-4,02 \mathrm{E}+00$ & $4,24 \mathrm{E}-01$ & $9,96 \mathrm{E}-01$ & $3,14 \mathrm{E}-01$ & $1,01 \mathrm{E}+00$ & $-4,02 \mathrm{E}+00$ & $4,24 \mathrm{E}-01$ & $9,96 \mathrm{E}-01$ \\
\hline IASM & $1,15 \mathrm{E}-01$ & $9,28 \mathrm{E}-01$ & $-4,02 \mathrm{E}+00$ & $2,60 \mathrm{E}-01$ & $2,08 \mathrm{E}-01$ & $1,15 \mathrm{E}-01$ & $9,28 \mathrm{E}-01$ & $-4,02 \mathrm{E}+00$ & $2,60 \mathrm{E}-01$ & $2,08 \mathrm{E}-01$ \\
\hline INASM & $1,95 \mathrm{E}-01$ & $4,64 \mathrm{E}-01$ & $-4,08 \mathrm{E}+00$ & $7,51 \mathrm{E}-02$ & $1,22 \mathrm{E}-01$ & $1,95 \mathrm{E}-01$ & $4,64 \mathrm{E}-01$ & $-4,08 \mathrm{E}+00$ & $7,51 \mathrm{E}-02$ & $1,22 \mathrm{E}-01$ \\
\hline RW & $1,61 \mathrm{E}-01$ & $3,75 \mathrm{E}-01$ & $-3,03 \mathrm{E}+00$ & $1,21 \mathrm{E}+00$ & $3,12 \mathrm{E}-02$ & $1,61 \mathrm{E}-01$ & $3,75 \mathrm{E}-01$ & $-3,03 \mathrm{E}+00$ & $1,21 \mathrm{E}+00$ & $3,12 \mathrm{E}-02$ \\
\hline LR & $8,93 \mathrm{E}-02$ & $3,22 \mathrm{E}-01$ & $-4,04 \mathrm{E}+00$ & $1,66 \mathrm{E}-01$ & $1,44 \mathrm{E}-01$ & $8,93 \mathrm{E}-02$ & $3,22 \mathrm{E}-01$ & $-4,04 \mathrm{E}+00$ & $1,66 \mathrm{E}-01$ & $1,44 \mathrm{E}-01$ \\
\hline Tour. & $2,31 \mathrm{E}-01$ & $1,21 \mathrm{E}+00$ & $-4,03 \mathrm{E}+00$ & $9,30 \mathrm{E}-02$ & $1,39 \mathrm{E}-01$ & $2,31 \mathrm{E}-01$ & $1,21 \mathrm{E}+00$ & $-4,03 \mathrm{E}+00$ & $9,30 \mathrm{E}-02$ & $1,39 \mathrm{E}-01$ \\
\hline OA & $2,44 \mathrm{E}-01$ & $5,15 \mathrm{E}-01$ & $-4,10 \mathrm{E}+00$ & $4,78 \mathrm{E}-02$ & $\mathbf{0 , 0 0 E}+\mathbf{0 0}$ & $\mathbf{2 , 4 4 E - 0 1}$ & $5,15 \mathrm{E}-01$ & $-4,10 \mathrm{E}+00$ & $4,78 \mathrm{E}-02$ & $0,00 \mathrm{E}+00$ \\
\hline N-OA & $\mathbf{3 , 5 4 E - 0 2}$ & $\mathbf{1 , 2 0 E}-\mathbf{0 1}$ & $-\mathbf{4 , 1 3 E}+\mathbf{0 0}$ & $\mathbf{5 , 9 8 E - 0 2}$ & $\mathbf{0 , 0 0 E}+\mathbf{0 0}$ & $\mathbf{3 , 5 4 E - 0 2}$ & $\mathbf{1 , 2 0 E}-\mathbf{0 1}$ & $\mathbf{- 4 , 1 3 E + 0 0}$ & $\mathbf{5 , 9 8 E - 0 2}$ & $\mathbf{0 , 0 0 E}+\mathbf{0 0}$ \\
\hline
\end{tabular}

Çizelge 5. Popülasyon büyüklüğü 100 için çok-modlu fonksiyonların sonuçları

\begin{tabular}{|c|c|c|c|c|c|c|c|c|c|c|}
\hline & \multicolumn{2}{|c|}{ Ackley } & \multicolumn{2}{|c|}{ Langermann } & \multicolumn{2}{|c|}{ Rastrigin } & \multicolumn{2}{|c|}{ Schwefel } & \multicolumn{2}{|c|}{ Branins } \\
\hline МЕTOT & Medyan & $\begin{array}{l}\text { Çeyreklikler } \\
\text { Açıklı̆ı̆ }\end{array}$ & Medyan & $\begin{array}{c}\text { Çeyreklikler } \\
\text { Açılkığı }\end{array}$ & Medyan & $\begin{array}{c}\text { Çeyreklikler } \\
\text { Açılkığı }\end{array}$ & Medyan & $\begin{array}{l}\text { Çeyreklikler } \\
\text { Açıklığı }\end{array}$ & Medyan & $\begin{array}{c}\text { Çeyreklikler } \\
\text { Açıklı̆ı̆ }\end{array}$ \\
\hline ASM & $3,39 \mathrm{E}-01$ & $3,27 \mathrm{E}-01$ & $-4,09 \mathrm{E}+00$ & $7,68 \mathrm{E}-02$ & $1,01 \mathrm{E}+00$ & $1,10 \mathrm{E}+00$ & $-8,20 \mathrm{E}+02$ & $1,10 \mathrm{E}+02$ & $3,99 \mathrm{E}-01$ & $3,96 \mathrm{E}-03$ \\
\hline NASM & $6,75 \mathrm{E}-02$ & $1,83 \mathrm{E}-01$ & $-4,12 \mathrm{E}+00$ & $5,19 \mathrm{E}-02$ & $9,95 \mathrm{E}-01$ & $1,00 \mathrm{E}+00$ & $-8,36 \mathrm{E}+02$ & $2,74 \mathrm{E}+01$ & 3,98E-01 & 4,93E-04 \\
\hline IASM & $4,62 \mathrm{E}-02$ & $2,79 \mathrm{E}-01$ & $-4,10 \mathrm{E}+00$ & $4,86 \mathrm{E}-02$ & $0,00 \mathrm{E}+00$ & $8,44 \mathrm{E}-02$ & $-8,38 \mathrm{E}+02$ & $5,14 \mathrm{E}-02$ & 3,98E-01 & $7,77 \mathrm{E}-04$ \\
\hline INASM & $5,58 \mathrm{E}-06$ & $2,82 \mathrm{E}-03$ & $-4,10 \mathrm{E}+00$ & $6,11 \mathrm{E}-02$ & $8,42 \mathrm{E}-07$ & $1,25 \mathrm{E}-02$ & $-8,38 E+02$ & $6,42 \mathrm{E}-02$ & 3,98E-01 & 9,08E-05 \\
\hline RW & $1,87 \mathrm{E}-02$ & $4,29 \mathrm{E}-02$ & $-3,66 \mathrm{E}+00$ & $2,88 \mathrm{E}-01$ & $1,65 \mathrm{E}-02$ & $7,65 \mathrm{E}-02$ & $-6,78 \mathrm{E}+02$ & $1,23 \mathrm{E}+02$ & 3,98E-01 & $2,45 E-03$ \\
\hline LR & $7,95 \mathrm{E}-03$ & $1,33 \mathrm{E}-01$ & $-4,12 \mathrm{E}+00$ & $4,55 \mathrm{E}-02$ & $1,30 \mathrm{E}-11$ & $7,47 \mathrm{E}-02$ & $-8,38 E+02$ & $9,52 \mathrm{E}-02$ & 3,98E-01 & $4,16 \mathrm{E}-04$ \\
\hline Tour. & $4,51 \mathrm{E}-03$ & $1,24 \mathrm{E}-01$ & $-4,08 \mathrm{E}+00$ & $6,11 \mathrm{E}-02$ & $2,87 \mathrm{E}-02$ & $7,35 \mathrm{E}-02$ & $-8,20 \mathrm{E}+02$ & $1,10 \mathrm{E}+02$ & 3,98E-01 & $5,39 \mathrm{E}-04$ \\
\hline OA & $2,51 \mathrm{E}-02$ & $5,65 \mathrm{E}-02$ & $-4,13 E+00$ & $2,77 \mathrm{E}-02$ & $0,00 \mathrm{E}+00$ & $0,00 \mathrm{E}+00$ & $-8,38 E+02$ & $7,72 \mathrm{E}-02$ & 3,98E-01 & 8,93E-04 \\
\hline $\mathrm{N}-\mathrm{OA}$ & $3,29 \mathrm{E}-03$ & $1,74 \mathrm{E}-02$ & $-4,13 E+00$ & $5,39 \mathrm{E}-02$ & $0,00 \mathrm{E}+00$ & $0,00 \mathrm{E}+00$ & $-8,38 E+02$ & $1,14 \mathrm{E}-03$ & 3,98E-01 & $4,42 \mathrm{E}-05$ \\
\hline
\end{tabular}

Bu bölümün başında da belirtildiği gibi çok modlu fonksiyonların lokal ekstremumlara sahip olması, optimizasyon algoritmalarının bu lokallerden birine yakalanma ihtimalini artırmaktadır. Yabancı algoritmaların popülasyona tamamıla yeni bireyler kazandırması lokal minimuma yakalanmanın önüne geçmektedir. $\mathrm{Bu}$ nedenle, önerilen saldırgan olmayan yabancı algoritması çok modlu fonksiyonlar için yapılan tüm testlerde en iyi ya da ikinci en iyi sonuçları üretmeyi başarmıştır.

\section{SONUÇ}

Agresif olmayan yabancı seçim algoritmasının performansı, önceden sunulmuş olan Saldırgan seçim yöntemleri (ASM ve IASM), Saldırgan olmayan seçim yöntemleri (NASM ve INASM), Yabancı seçim yöntemi (Outlander) ile yaygın olarak kullanılan seçim yöntemlerinin; rulet tekeri
(RW), doğrusal siralama (LR) ve turnuva, performansları ile karşılaştırılmıştır.

Yapılan testlerin sonucunda, geliştirilen Saldırgan olmayan yabancı seçim yönteminin (N-OA), tüm testlerde yabancı seçim yöntemine (Outlander) göre daha iyi sonuçlar verdiği gözlemlenmiştir. Benzer şekilde, düşük popülasyonlarda N-OA, tüm testlerde kıyaslanan diğer tüm seçim yöntemleri içinde en iyi sonuçları vermiştir.

Popülasyon büyüklüğünün yüksek tutulduğu testlerde ise N-OA çok modlu fonksiyonların tamamında, Ackley hariç, en iyi sonucu elde etmiştir. Tek modlu fonksiyonlarda ise, beş fonksiyonun üçünde en iyi, kalan ikisinde de en iyi ikinci sonuçları üreterek diğer seçim yöntemlerine göre üstün olduğunu kanıtlamıştır. 


\section{TEŞEKKÜR}

Bu çalışma Çukurova Üniversitesi Bilimsel Araştırma Projeleri Koordinasyon Birimince desteklenmiştir (Proje Numarası: 8463).

\section{KAYNAKLAR}

1. Holland, J. 1975. Adaptation in Natural and Artificial Systems: An Introductory Analysis with Applications to Biology, Control and Artificial Intelligence, The University of Michigan Press, viii 183.

2. Goldberg, D.E. 1989. Genetic Algorithms in Search Optimization and Machine Learning, Addison-Wesley Longman Publishing Co., Inc. Boston, MA, USA.

3. Mitchell, M. 1996. An Introduction to Genetic Algorithms, A Bradford Book The MIT Press.

4. Gençal, M.C., Oral, M. 2017. Outlander Algorithm Based on Integrated Aggressive Selection Method, International Journal of Science and Research (IJSR), Volume 6 Issue 11, 1673-1679, DOI: 10.21275/ART20178369

5. Grefenstette, J.J., Baker, J.E. 1989. How Genetic Algorithms Work: a Critical Look at Implicit Parallelism, Proceedings of the Third International Conference on Genetic Algorithms, 20-27.

6. Oral, M., Gençal, M.C., 2017. Genetik Algoritma için İyileştirilmiş Saldırgan ve Bütünleşik Saldırgan Seçim Yöntemleri, Proceeding of UBMK: 2nd International Conference on Computer Sciences and Engineering, 320-325.

7. Goldberg, D.E., 1990. A Note on Boltzmann Tournament Selection for Genetic Algorithms and Population-oriented Simulated Annealing. Complex Systems 4.4, 445-460.

8. Harik, G.R. 1995. Finding Multimodal Solutions using Restricted Tournament Selection, ICGA, 24-31.

9. Matsui, K. 1999. New Selection Method to Improve the Population Diversity in Genetic Algorithms. In: Systems, Man, and Cybernetics, IEEE SMC'99 Conference Proceedings. 1999 IEEE International Conference on. IEEE, 625-630.
10. De La Maza, Tidor, B. 1991. Increased Flexibility in Genetic Algorithms: The use of Variable Boltzmann Selective Pressure to Control Propagation, Proceeding of ORSA Conference: Computer Science and Operations Research: New Developments in Their Interfaces, 425-440.

11. Pohlheim, H. 1995. The Multipopulation Genetic Algorithm: Local selection and Migration, Technical Report, Technical University Ilmenau.

12. Molga, M., Smutnicki, C. 2005. Test Functions for Optimization Needs, available: http://www.zsd.ict.pwr.wroc.pl/files/docs/funct ions.pdf.

13. Lobo, F.G., Goldberg, D. 2004. The ParameterLess Genetic Algorithm in Practice, Information Sciences, 167(1-4), 217-232. 
